\title{
Effect of Yttrium Additions in Relation to Oxygen Content on Glass Formation in the $\mathrm{Zr}_{50} \mathrm{Cu}_{40} \mathrm{Al}_{10}$ Alloy
}

\author{
KRZYSZTOF PAJOR, TOMASZ KOZIEŁ, BOGDAN RUTKOWSKI, \\ GRZEGORZ CIOS, PIOTR BŁYSKUN, DOROTA TYRAŁA, PIOTR BAŁA, \\ and ANNA ZIELIŃSKA-LIPIEC
}

The effect of yttrium additions on the glass formation of the $\mathrm{Zr}_{50} \mathrm{Cu}_{40} \mathrm{Al}_{10}$ alloy with high oxygen content was investigated. Unlike other reports showing the positive effect of alloying Zr-based alloys with a few percent of rare earth elements, we examined the Y-to-oxygen ratios. As calculated, a stoichiometric amount of yttrium (2808 at $\mathrm{ppm})$ is required to bind all the oxygen (4212 at ppm) to form the $\mathrm{Y}_{2} \mathrm{O}_{3}$. Additionally, the influence of half (1404 at ppm) and double stoichiometric (5616 at ppm) levels of yttrium, with respect to the measured oxygen content to be bound was evaluated. The Y-doped alloys were synthesized by arc melting, followed by suction casting into copper molds with conical and rod cavities. The critical diameter of the undoped alloy was below $3 \mathrm{~mm}$, while stoichiometric and double stoichiometric yttrium concentrations allowed to obtain 5 and $7 \mathrm{~mm}$ diameter glassy samples, respectively. Microstructure observations confirmed the scavenging effect of yttrium, leading to the formation of a cubic ( $I a \overline{3}$ space group) yttrium sesquioxide. The glass forming ability of the alloys was additionally determined based on differential thermal analysis, allowing to propose the best indicator for the studied $\mathrm{Zr}-\mathrm{Cu}-\mathrm{Al}$ alloys.

https://doi.org/10.1007/s11661-020-05875-1

(C) The Author(s) 2020

\section{INTRODUCTION}

ZR-BASED bulk metallic glasses (BMGs) belong to the group of modern metallic materials. The fabrication of such materials, i.e., obtaining an amorphous structure, requires sufficiently fast cooling rates during solidification to bypass the crystallization process. In comparison to their crystalline counterparts, BMGs are characterized by superior mechanical, physical and chemical properties. ${ }^{[1]}$ These characteristics make them a promising structural and functional material for many engineering applications, e.g., sport goods,

KRZYSZTOF PAJOR, TOMASZ KOZIEL, BOGDAN RUTKOWSKI, DOROTA TYRAŁA, and ANNA ZIELIŃSKALIPIEC are with the Faculty of Metals Engineering and Industrial Computer Science, AGH University of Science and Technology, Al. Mickiewicza 30, 30-059 Krakow, Poland. Contact e-mail: kpajor@agh.edu.pl GRZEGORZ CIOS is with the Academic Centre for Materials and Nanotechnology, AGH University of Science and Technology, Al. Mickiewicza 30, 30-059 Krakow, Poland. PIOTR BŁYSKUN is with the Warsaw University of Technology, Faculty of Material Science and Engineering, Wołoska 141, 02-507 Warsaw, Poland. PIOTR BAŁA is with the Faculty of Metals Engineering and Industrial Computer Science, AGH University of Science and Technology and also with the Academic Centre for Materials and Nanotechnology, AGH University of Science and Technology.

Manuscript submitted January 31, 2020.

Article published online June 22, 2020 high-performance springs, micro-geared motor parts, pressure sensors, biomedical application, etc. . $^{[2,3]}$

Unfortunately, the fabrication of Zr-based BMGs is very expensive, due to the necessity of using high purity constituent elements and strict processing conditions. Special attention must be paid to oxygen content, as this element dramatically reduces the alloy's glass forming ability (GFA) and deteriorates its mechanical properties. ${ }^{[4-8]}$ Such a dramatic drop in the GFA is caused by the formation of oxides or other oxygen-induced inclusions, acting as perfect heterogeneous nucleation sites during solidification. ${ }^{[9-12]}$ The $\mathrm{ZrO}_{2}$ oxide is regarded as a nucleation catalyst in Zr-based alloys. This oxide exists in three crystallographic forms: monoclinic $\alpha$ $\mathrm{ZrO}_{2}$, which is thermodynamically stable up to $1478 \mathrm{~K}$, tetragonal $\beta \mathrm{ZrO}_{2}$ stable between $1475 \mathrm{~K}$ and $2650 \mathrm{~K}$, and finally cubic $\gamma \mathrm{ZrO}_{2}\left(\mathrm{CaF}_{2}\right.$ - type $)$ phase, which is stable up to the melting point, $2983 \mathrm{~K}^{\left[{ }^{[13]}\right.}$

In our previous work, we studied the $\mathrm{Zr}_{50} \mathrm{Cu}_{40} \mathrm{Al}_{10}$ alloy with two oxygen levels, $194 \pm 26 \mathrm{wt}$ ppm and 918 $\pm 72 \mathrm{wt}$ ppm. ${ }^{[4]}$ The critical diameter $\mathrm{D}_{\mathrm{c}}$ (the maximum amorphous thickness) of this alloy was determined to be $8 \mathrm{~mm}$ and below $3 \mathrm{~mm}$ for the alloy with low and high oxygen contents, respectively. If the sample diameter exceeded the critical size, the metastable $\mathrm{CuZr}$ phase, with a small amount of the $\tau_{3}\left(\mathrm{Zr}_{51} \mathrm{Cu}_{28} \mathrm{Al}_{21}\right)$ phase, were observed for the low oxygen variant. In comparison, only the $\tau_{3}$ phase was present in the high oxygen 
Table I. Chemical Composition of Investigated Alloys

\begin{tabular}{|c|c|c|c|c|c|}
\hline \multirow[b]{2}{*}{ Alloy Designation } & \multirow[b]{2}{*}{ Y-to-Oxygen Atomic Ratio } & \multicolumn{4}{|c|}{ Chemical Composition (At. Pct) } \\
\hline & & $\mathrm{Zr}$ & $\mathrm{Cu}$ & $\mathrm{Al}$ & $\mathrm{Y}$ \\
\hline $\mathrm{B}$ & - & 50 & 40 & 10 & - \\
\hline $\mathrm{B} 1 / 3$ & $1: 3$ & 49.930 & 39.944 & 9.986 & 0.140 \\
\hline B $2 / 3$ & $2: 3$ & 49.860 & 39.888 & 9.972 & 0.281 \\
\hline $\mathrm{B} 4 / 3$ & $4: 3$ & 49.719 & 39.775 & 9.944 & 0.562 \\
\hline
\end{tabular}

level sample. According to the ternary phase diagram, ${ }^{[14]}$ $\tau_{3}$ is the first solidifying phase for this chemical composition. This shows that oxygen impurities facilitate the $\tau_{3}$ phase formation by providing heterogeneous nucleation sites during solidification.

It is not possible to completely eliminate oxygen from raw elements, due to the high chemical affinity of zirconium and oxygen. Moreover, high purity and Hf-free zirconium is not commercially available, as it exhibits a very low neutron capture cross-section, which made it a strategic material for nuclear power plant applications. ${ }^{[15]}$ Commercially available $\mathrm{Zr}$-sponge can contain more than $1000 \mathrm{wt}$ ppm of oxygen.

Therefore, an idea of doping low-purity (high oxygen) alloys with rare-earth elements (REEs) was proposed by Zhang et al. ${ }^{[16]}$ Such elements, with higher affinities to oxygen than zirconium, can act as an oxygen scavenger and form a less harmful oxide. So far, various glass forming systems doped with different rare-earth elements have been investigated. ${ }^{[16-24]}$ Significant attention was paid to yttrium, which increases the GFA of $\mathrm{Zr}-\mathrm{Al}-\mathrm{Ni}-\mathrm{Cu}^{[20]} \quad \mathrm{Zr}-\mathrm{Co}-\mathrm{Al},{ }^{[21]}$ Zr-Ti-Cu-Ni-Be, ${ }^{[16]}$ $\mathrm{Cu}-\mathrm{Zr}-\mathrm{Al}{ }^{[22]}$ alloys. However, yttrium additions and oxygen concentrations were not correlated. Additionally, yttrium was changed monotonically (1, 2, 3 pct, etc.), meaning that the total effect of yttrium is a sum of scavenging and alloying effects. As REEs exhibit strong affinities with oxygen, their scavenging effect should be studied with respect to the known, to be bound, oxygen content in the alloy. More detailed investigations were carried out by Kündig et al. ${ }^{[19]}$ where the effects of Sc and La additions on the GFA were studied in the $\mathrm{Zr}_{52.5} \mathrm{Cu}_{17.9} \mathrm{Ni}_{14.6} \mathrm{Al}_{10} \mathrm{Ti}_{5}$ alloy that could be cast into $4 \mathrm{~mm}$ glassy sample without the necessity of doping. Small Sc additions, preceded by careful oxygen measurements, to the undoped alloy significantly increased the $\mathrm{D}_{\mathrm{c}}$. The highest GFA was obtained for 0.03 to 0.06 pet of Sc, reaching $\mathrm{D}_{\mathrm{c}}$ of almost $12 \mathrm{~mm}$. This $\mathrm{Sc}$ contents range corresponds to the stoichiometric and double stoichiometric level required to form the $\mathrm{Sc}_{2} \mathrm{O}_{3}$ oxide.

In this paper, we systematically studied the effect of yttrium additions to the $\mathrm{Zr}_{50} \mathrm{Cu}_{40} \mathrm{Al}_{10}$ alloy, with high oxygen content, on its glass-forming ability. Yttrium is generally considered a heavy REE, due to its similar ionic radius to Dy. ${ }^{[25]}$ Similarly to other REEs, the $\mathrm{Y}_{2} \mathrm{O}_{3}$ sesquioxide is the most stable type of oxide. The Gibbs-free energy of yttrium oxide formation is significantly lower in comparison to zirconium oxide within the entire temperature range: $\mathrm{Y}_{2} \mathrm{O}_{3}$ : $-1816.6 \mathrm{~kJ} / \mathrm{mol}$ and $\mathrm{ZrO}_{2}$ : $-1042.8 \mathrm{~kJ} / \mathrm{mol}$ at $298 \mathrm{~K}$;
$\mathrm{Y}_{2} \mathrm{O}_{3}:-1392.3 \mathrm{~kJ} / \mathrm{mol}$ and $-763.7 \mathrm{~kJ} / \mathrm{mol}$ at $1800 \mathrm{~K} \cdot{ }^{[26]}$ The crystallographic structure of $\mathrm{Y}_{2} \mathrm{O}_{3}$ will play a key role in the formation of undesirable phases during solidification. During heating, these sesquioxides polymorphically transform from a cubic (Ia $\overline{3}$ space group) to a high-temperature hexagonal ( $\mathrm{Pb}_{3} / \mathrm{mmc}$ space group) structure at $2600 \pm 30 \mathrm{~K}$, becoming stable until reaching its melting point $(2712 \mathrm{~K}) .^{[27]}$ Two other forms of $\mathrm{Y}_{2} \mathrm{O}_{3}$ can be found at higher pressures: monoclinic above $13 \mathrm{GPa}$ and hexagonal above $24.5 \mathrm{GPa}^{[28]} \mathrm{As}$ these two phases do not occur at ambient pressure, they are not considered in the present study.

\section{MATERIAL AND METHODS}

Based on our previous work, ${ }^{[4]}$ the oxygen level in the undoped $\mathrm{Zr}_{50} \mathrm{Cu}_{40} \mathrm{Al}_{10}$ alloy (918 \pm 72 wt ppm) was recalculated into atomic percentage (4213 at ppm) and this amount of oxygen is intended to be bound by yttrium. The stoichiometric yttrium concentration to bind all oxygen into the $\mathrm{Y}_{2} \mathrm{O}_{3}$ oxide (herein referred to as B2/3) was calculated to be 0.281 at. pct. Moreover, half $(\mathrm{B} 1 / 3)$ and double stoichiometric (B4/3) levels of yttrium with respect to oxygen content were studied. The chemical compositions of the investigated alloys and sample designations with respect to the Y-to-oxygen ratios are presented in Table I. The alloys were synthesized by means of arc melting and suction-casting into copper mold cavities in a Ti-gettered argon atmosphere (6 N) using low-purity $\mathrm{Zr}$ (99.8 pct) and high purity $\mathrm{Cu}$ (99.99 pct), Al (99.999 pct) and Y (99.9 pct). First, cone-shaped samples were produced to find the approximate $\mathrm{D}_{\mathrm{c}}$, which was determined using a threshold of 5 pct crystalline material. ${ }^{[19]}$ As the critical diameter obtained from the parallel-edge molds may differ from the conical ones, ${ }^{[4,29]}$ a series of rod samples with a gradually increasing diameter were cast and characterized by microstructure observations and X-ray diffraction (XRD, Panalytical Empyrean diffractometer) with $\mathrm{Cu} \mathrm{K}_{\alpha}$ radiation. The rod sample with the highest diameter, in the absence of sharp Bragg peaks on XRD, was assumed to be amorphous, and this diameter was taken as the critical value. Critical diameter values determined on conical and rod samples are designated as $D_{c}^{c}$ and $D_{c}^{r}$, respectively.

All prepared samples were cut (cones-longitudinally, rods - crosswise), grinded ( $\mathrm{SiC}$ paper up to 7000-grit), polished (mixture of colloidal silica and hydrogen peroxide), etched $\left(25 \mathrm{ml} \mathrm{H} 2 \mathrm{O}+22.5 \mathrm{ml} \mathrm{HNO}_{3}+5\right.$ drops $\mathrm{HF}$ ), and then studied using optical microscope 
(Nikon ECLIPSE LV150N). Scanning electron microscopy (SEM) observations were carried out using Versa 3D (FEI) microscope equipped with an energy dispersive spectrometer (EDS). A high-resolution scanning transmission electron microscope (FEI, Titan Cubed G2 60-300) equipped with EDX ChemiSTEM was used for detailed observations of small precipitates. Lamella for STEM study was extracted using the SEM-FIB technique (ZEISS NEON CrossBeam 40EsB).

The GFA indicators were determined based on differential thermal analysis (DTA, Setaram Labsys). The calorimeter was carefully calibrated before measurements. After resetting the correction coefficients in the DTA software, new melting measurements of the reference elements ( $\mathrm{Sn}, \mathrm{Zn}, \mathrm{Al}, \mathrm{Cu}$, and $\mathrm{Ni}$ ) were performed at different heating rates $(10,20$, and $40 \mathrm{~K} /$ min). Based on the registered onset melting points and thermal effects, new correction coefficients were entered in the analyzer software. DTA measurements were conducted on thin slices cut from the middle of the as-cast samples using $100 \mu \mathrm{l}$ alumina pans at a constant heating rate of $20 \mathrm{~K} / \mathrm{min}$ and protective $\operatorname{argon}(5 \mathrm{~N}$ purity) gas flow with $20 \mathrm{ml} / \mathrm{min}$.

All characteristic temperatures $\left(T_{\mathrm{g}}\right.$-glass transition, $T_{x}$-onset of crystallization, $T_{\mathrm{p}}$-peak of crystallization, $T_{\mathrm{s}}$ and $T_{\mathrm{f}}$-start and finish of the eutectoid transformation, $T_{\mathrm{m}}$-solidus, $T_{1}$-liquidus) were determined by the DTA software. $T_{\mathrm{g}}$ temperatures were estimated as the inflection points on the DTA curves. Based on these values, several GFA indicators were evaluated: $\Delta T_{\mathrm{xg}}=$ $T_{\mathrm{x}}-T_{\mathrm{g},}{ }^{[30]} T^{,}{ }_{\mathrm{rg}}=T_{\mathrm{g}} / T_{1}{ }^{[31]} \gamma=T_{\mathrm{x}} /\left(T_{\mathrm{g}}+T_{1}\right){ }^{[32]} \gamma_{\mathrm{m}}=$ $\left(2 T_{\mathrm{x}}-T_{\mathrm{g}}\right) / T_{1},{ }^{[33]} \omega_{4}=\left(2 T_{\mathrm{x}}-T_{\mathrm{g}}\right) /\left(T_{1}+T_{\mathrm{x}}\right)^{[34]}$ and the $\chi=\left[\left(T_{\mathrm{x}}-T_{\mathrm{g}}\right) /\left(T_{1}-T_{\mathrm{x}}\right)\right] \cdot\left[T_{\mathrm{x}} /\left(T_{1}-T_{\mathrm{x}}\right)\right]^{1.47 \cdot[35]}$

\section{RESULTS AND DISCUSSION}

\section{A. Critical Diameter Determination}

Microstructures of the doped alloys cast in the form of cones are presented in Figure 1 . In the case of $\mathrm{B} 1 / 3$ and B2/3 alloys (Figure 1(a)), crystalline inclusions were observed across their entire longitudinal section, similarly to the reference (undoped) alloy. ${ }^{[4]}$ SEM observation revealed uniform distribution of crystalline inclusions and yttrium oxides, even at the bottom part of the cones (Figures 1(b), (c)). This effect can be observed, as the lateral surface of the cone is not parallel to suction direction (taper angle of $10 \mathrm{deg}$ ), which causes intense convection in the melt and spreading of crystalline inclusions in the whole volume. Therefore, it was not possible to accurately determine the $D_{c}^{c}$ for these variants. Similar oxides were also observed in the case of double stoichiometric amount of yttrium with respect to the measured oxygen content to be bound (B4/3). However, their volume fraction was significantly lower (Figure 1(d), (e)) and the critical diameter was estimated as $D_{c}^{c}=5 \mathrm{~mm}$.

Critical diameters of the doped alloys were determined on rod samples. Figure 2 shows XRD patterns of the reference $\mathrm{Zr}_{50} \mathrm{Cu}_{40} \mathrm{Al}_{10}$ alloy ( $3 \mathrm{~mm}$ diameter rod) and a series of doped alloys cast in the form of $4 \mathrm{~mm}$

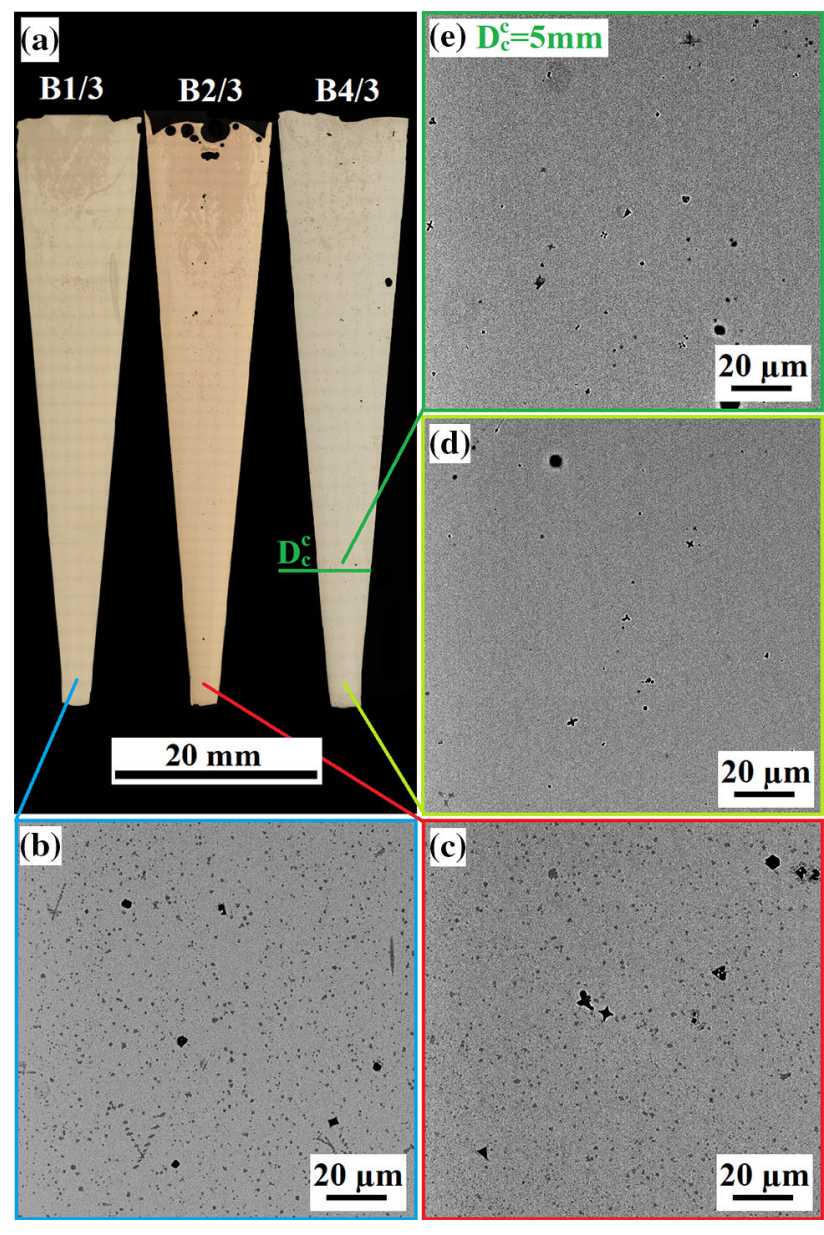

Fig. 1-Longitudinal microstructures (light microscopy) of B1/3, B2/ 3 and $\mathrm{B} 4 / 3$ alloys cast in the form of cones $(a)$ with magnified SEM micrographs from the bottom end of the cones: (b) B1/3, (c) B2/3, $(d, e) \mathrm{B} 4 / 3$.

and $5 \mathrm{~mm}(\mathrm{~B} 1 / 3), 5 \mathrm{~mm}$ and $6 \mathrm{~mm}(\mathrm{~B} 2 / 3)$, as well as $7 \mathrm{~mm}$ and $8 \mathrm{~mm}(\mathrm{~B} 4 / 3)$ diameter rods. A characteristic amorphous halo was observed in all samples, however, in the case of sample diameter $D=D_{c}^{r}$, no crystalline peaks could be detected. The positive effect of yttrium additions on the amorphous thickness of the $\mathrm{Zr}_{50} \mathrm{Cu}_{40} \mathrm{Al}_{10}$ alloy is evident even in the case of insufficient amounts to bind all oxygen. The addition of only 0.140 at. pet yttrium (B1/3 - half stoichiometric level required to bind all oxygen) to the alloy containing $918 \pm 72 \mathrm{wt} \mathrm{ppm}$ of oxygen allowed to obtain a $4 \mathrm{~mm}$ diameter glassy sample. A lower cooling rate in the higher diameter sample $(5 \mathrm{~mm})$ did not allow to bypass the crystallization process and partial crystallization of the $\tau_{3}$ phase was confirmed. This phase was identified by comparison of $2 \theta$ positions with the one in Reference. ${ }^{[12]}$ As there are no crystallographic data of this phase, Yokoyama et at. synthesized a sample with a composition corresponding to this phase and compared diffraction peaks of a homogenized sample with the peaks coming from the partially crystallized sample.

A slightly higher critical diameter $\left(D_{c}^{r}=5 \mathrm{~mm}\right)$ was obtained using the stoichiometric level of yttrium addition (0.281 at. pct) required to bind all oxygen. 


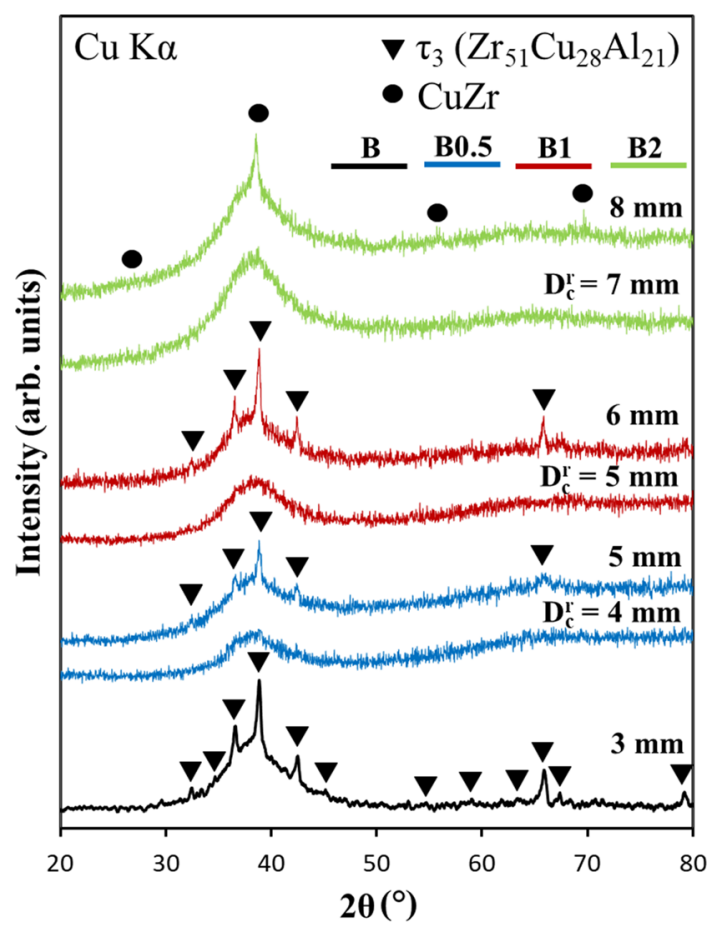

Fig. 2-XRD patterns of the $\mathrm{Zr}_{50} \mathrm{Cu}_{40} \mathrm{Al}_{10}$ reference (undoped) $\mathrm{B}$ alloy with high oxygen level (black pattern- reprinted with permission from Ref. [4] (C) Elsevier) and $\mathrm{Zr}-\mathrm{Cu}-\mathrm{Al}-\mathrm{Y}$ alloys with different Y-to-oxygen ratios: half stoichiometric (B1/3; blue patterns); stoichiometric (B2/3; red patterns) and double stoichiometric (B4/3; green patterns) (Color figure online).

The further increase in yttrium concentration to the double stoichiometric level, allowed to obtain a similar value of critical diameter $\left(D_{c}^{r}=7 \mathrm{~mm}\right)$ to that value determined in the low oxygen alloy $\left(8 \mathrm{~mm}^{[4]}\right)$. Moreover, in the case of $D_{c}^{r}+1 \mathrm{~mm}$ sample, the CuZr phase was detected instead of the $\tau_{3}$ phase. The presence of a cubic primitive $\mathrm{CuZr}$ phase ( $P m \overline{3} m$ space group) dispersed in the glassy matrix is known to be an effective method of enhancing plasticity of CuZr-based alloys. $^{[36,37]}$

Our results show that the stoichiometric amount of yttrium addition in relation the measured oxygen content is not sufficient to bind all oxygen. This is most probably related to the partial dissolution of yttrium in the matrix and/or additional oxidizing coming from yttrium itself. To prevent oxygen-induced formation of the $\tau_{3}$ phase, excess yttrium is required. The formation of the $\tau_{3}$ phase during solidification depletes the remaining melt in $\mathrm{Zr}$ and reduced GFA. If the amount of yttrium was sufficient to bind all oxygen, the critical diameter would be close to the value determined in the high purity (low oxygen) alloy.

\section{B. Microstructure Observations of Doped Alloys}

SEM observations of B2/3 and B4/3 alloys cast in the form of rods with sizes corresponding to $D_{c}^{r}$ and $D_{c}^{r}+1 \mathrm{~mm}$ showed the presence of yttrium oxides in all samples (dark contrast in Figure 3), as confirmed by the EDS spectrum in Figure 3(b). It should be noted, that the absence of sharp Bragg peaks on the XRD pattern was taken as the amorphicity criterion. In fact, the oxides were observed in the rod samples corresponding to $D_{c}^{r}$, however, their volume fraction was below XRD detection limit. For the $D_{c}^{r}+1 \mathrm{~mm}$ variants, an additional $\tau_{3}$ phase (grey contrast) was identified for the stoichiometric concentration of yttrium (Figure 3(b)), whereas for the B4/3 alloy, CuZr crystallites embedded in the amorphous matrix were observed (Figure 3(d)). It is worth noting that the $\mathrm{CuZr}$ phase crystallized on the oxide array, which indicates that the yttrium oxide can also act as a nucleation site. In contrary to the $\tau_{3}$ phase, which was uniformly distributed in the whole sample, the $\mathrm{CuZr}$ was observed only in the central part of the rods.

The B2/3 alloy in the form of $6 \mathrm{~mm}$ diameter rod was submitted to detailed (S)TEM observations. Figure 4 shows high-angle annular dark-field (HAADF) image and EDS elemental distribution maps. It is clear that the precipitate is composed of yttrium and oxygen. Figure 5(a) shows a high-resolution scanning transmission electron microscopy (HRSTEM) image of this phase in HAADF contrast. The electron diffraction investigation (Figure 5(b)) proved that this particle is the $\mathrm{Y}_{2} \mathrm{O}_{3}$ oxide with a cubic $I a \overline{3}$ - space group and a lattice parameter of $10.6(0) \AA$. This type of $\mathrm{Y}_{2} \mathrm{O}_{3}$ is thermodynamically stable below $2600 \mathrm{~K} .^{[27]}$ The EDS analysis of the area near the oxide showed slightly increased oxygen contents, as well as enrichment of Al at the expense of copper compared to the matrix. Such composition corresponds to the $\tau_{3}$ phase $\left(\mathrm{Zr}_{51} \mathrm{Cu}_{28} \mathrm{Al}_{21}\right)$. Figures 5(c) and (d) show HRSTEM-HAADF images and corresponding electron diffraction patterns of this phase. As there is no reference pattern of the $\tau_{3}$ phase in the database, the diffraction spots are not indexed. Figures 5(e) and (f) show HRSTEM-HAADF images of the interface between $\tau_{3}$ and $\mathrm{Y}_{2} \mathrm{O}_{3}$ phases, with corresponding electron diffraction patterns. These investigations proved that there is no coherence between these phases, which is favorable if nucleation is expected to be avoided during solidification. A typical "salt and pepper" contrast for the amorphous structure is shown in Figure 5(g). Some medium-range order (MRO) zones form a network of dark regions in the bright matrix, with an area of approx. $8 \mathrm{~nm}^{2}$. The electron diffraction pattern (Figure 5(h)) of the amorphous region shown in Figure 5(g) consists of a typical amorphous halo. TEM studies and EDS analysis clearly prove that the observed oxides are the low-temperature cubic $\mathrm{Y}_{2} \mathrm{O}_{3}$ phase. If yttrium is added to the alloy, it binds with oxygen and forms yttrium oxide in the melt, due to the Gibbs free energy of $\mathrm{Y}_{2} \mathrm{O}_{3}$ formation being significantly lower than that of $\mathrm{ZrO}_{2}(-1392.3$ vs. $-763.7 \mathrm{~kJ} / \mathrm{mol}$ at $1800 \mathrm{~K}$ $\left.{ }^{[26]}\right)$. As the solidification range of $\mathrm{Zr}$-based alloys is between $1200 \mathrm{~K}$ and $700 \mathrm{~K}$, the crystallographic type of inclusions dispersed in the undercooled melt within this temperature range plays a key role. Apart from rare-earth elements being considered as oxygen scavengers, ${ }^{[17]}$ it is also clear that any crystalline phase dispersed in the melt promotes heterogeneous nucleation during solidification. As shown in Figure 3(d), the 

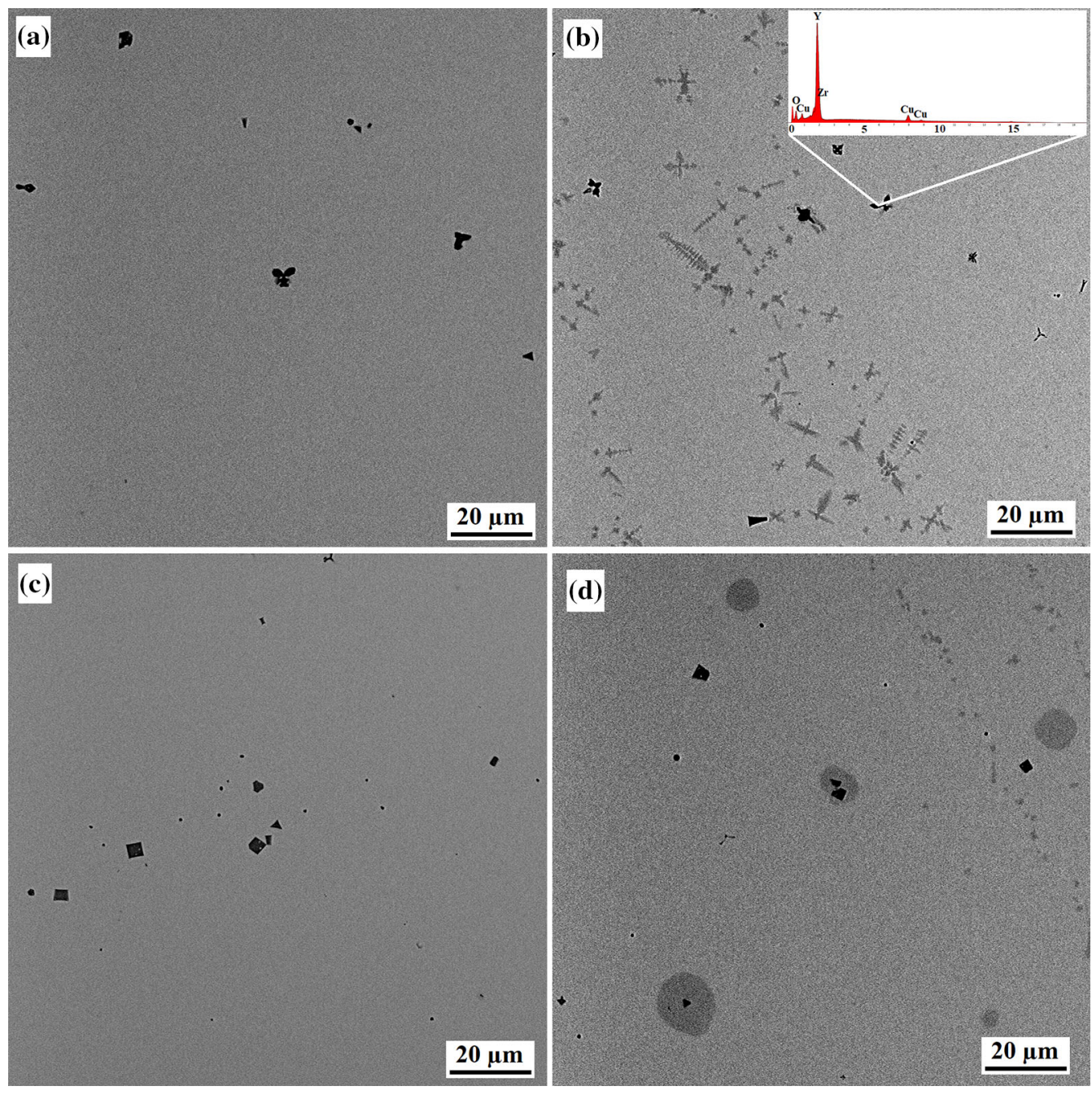

Fig. 3-SEM-BSE images of doped alloys: (a) B2/3, $D=D_{c}^{r}=5 \mathrm{~mm},(b) \mathrm{B} 2 / 3, D=6 \mathrm{~mm},(c) \mathrm{B} 4 / 3, D=D_{c}^{r}=7 \mathrm{~mm},(d) \mathrm{B} 4 / 3, D=8 \mathrm{~mm}$. Inset in $(b)$ shows EDS spectrum of the yttrium oxide.

$\mathrm{Y}_{2} \mathrm{O}_{3}$ dispersed in the melt facilitates $\mathrm{CuZr}$ phase crystallization. However, this phase was only observed in a higher diameter sample, and a relatively low-cooling rate is sufficient to avoid its formation. In turn, the $\tau_{3}$ phase was observed even in the lower diameter (rapidly solidified) samples with high oxygen, especially if the yttrium content was insufficient to bind the oxygen. Therefore, it should be noted that yttrium acts as an oxygen scavenger, leading to stabilization of the supercooled liquid and enhancement of the GFA, as well as the formation of yttrium oxides do not facilitate heterogeneous nucleation during solidification.

\section{Glass Forming Ability}

As the determination of the critical diameter is a time-consuming process, thermal analysis during heating is commonly used to describe the glass forming ability of a given alloy. Despite characteristic temperatures being higher in comparison to the applied cooling conditions (during solidification), they allow to easily estimate GFA. The DTA curves recorded during heating of the undoped $\mathrm{Zr}_{50} \mathrm{Cu}_{40} \mathrm{Al}_{10}$ alloy $(\mathrm{B} ; 3 \mathrm{~mm}$ diameter rod) and its doped variants, with sizes corresponding to their $D_{c}^{r}$ values, are plotted in Figure 6. All samples exhibit a distinct glass transition temperature, followed by a supercooled liquid region and two-stage crystallization. According to our previous work, ${ }^{[4]}$ increased oxygen levels lower the temperature of the first crystallization peak $\left(T_{\mathrm{p} 1}\right)$ from $781 \mathrm{~K}$ to $764 \mathrm{~K}$, and increase the second one $\left(T_{\mathrm{p} 2}\right)$ from $934 \mathrm{~K}$ to $967 \mathrm{~K}$. In the case of the doped alloys, the increase in yttrium concentration shifted the crystallization events to higher temperatures, while the glass transition temperature is almost unchanged. A distance between these two temperatures $\left(\Delta T_{\mathrm{xg}}=T_{\mathrm{x}}-\mathrm{T}_{\mathrm{g}}\right)$ is referred to as the supercooled liquid region and is one of the GFA indicators (the wider $\Delta T_{\mathrm{xg}}$ the higher the GFA). The temperature of the first crystallization peak increases from $764 \mathrm{~K}$ (curve B) to $775 \mathrm{~K}, 777 \mathrm{~K}$, and $792 \mathrm{~K}$ for $\mathrm{B} 1 / 3$, B2/3 and $\mathrm{B} 4 / 3$, respectively. The second crystallization peak did not change for $\mathrm{B} 1 / 3$ and B2/3 (approx. $967 \mathrm{~K}$ ), however, in the case of $\mathrm{B} 4 / 3$, it is too smooth to be accurately determined. Further heating leads to an 


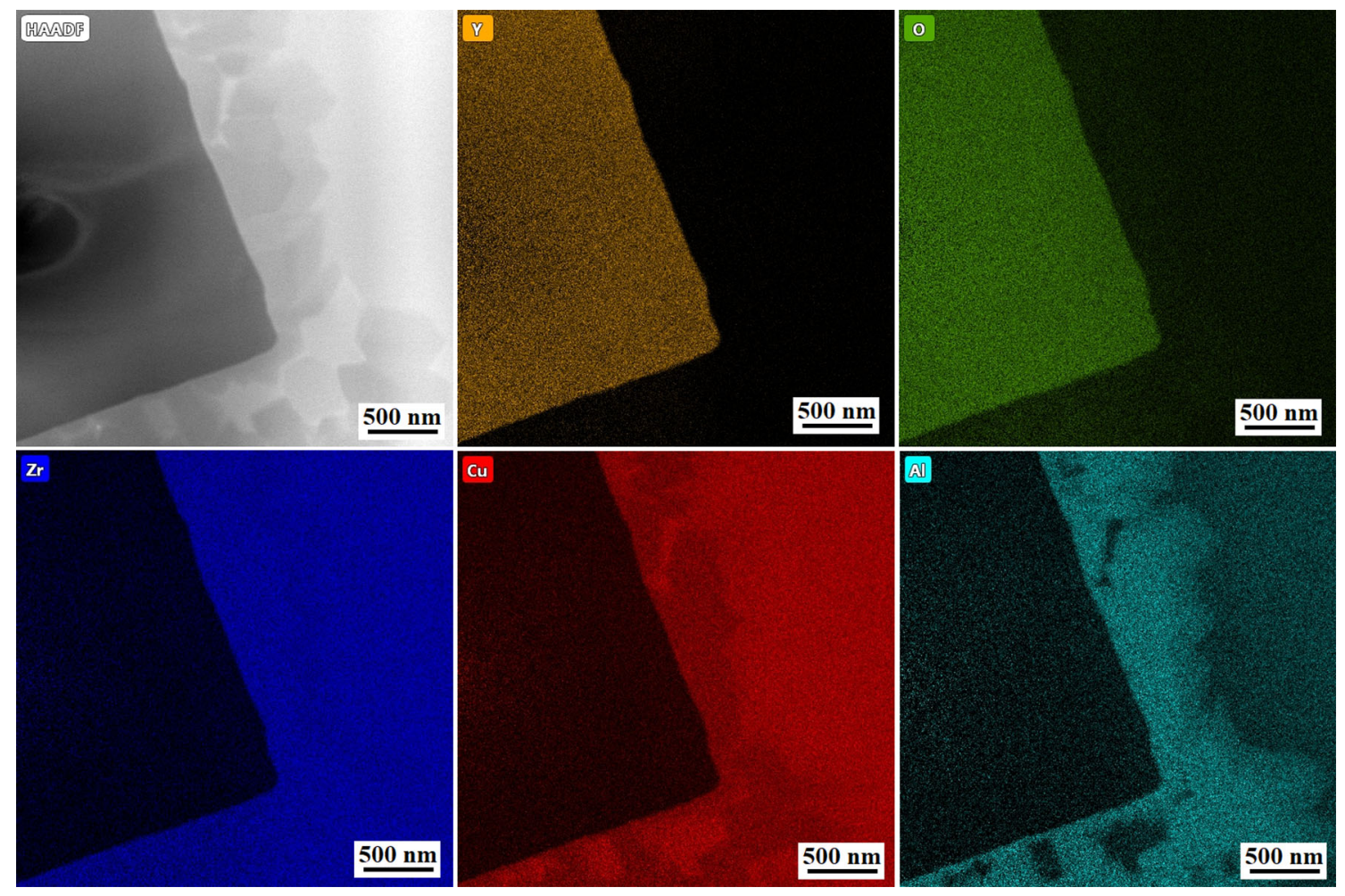

Fig. 4-HAADF imaging and EDS elemental distribution maps of the $\mathrm{B} 2 / 3$ alloy $\left(\mathrm{Zr}_{49.860} \mathrm{Cu}_{39.890} \mathrm{Al}_{9.972} \mathrm{Y}_{0.281}\right)$.
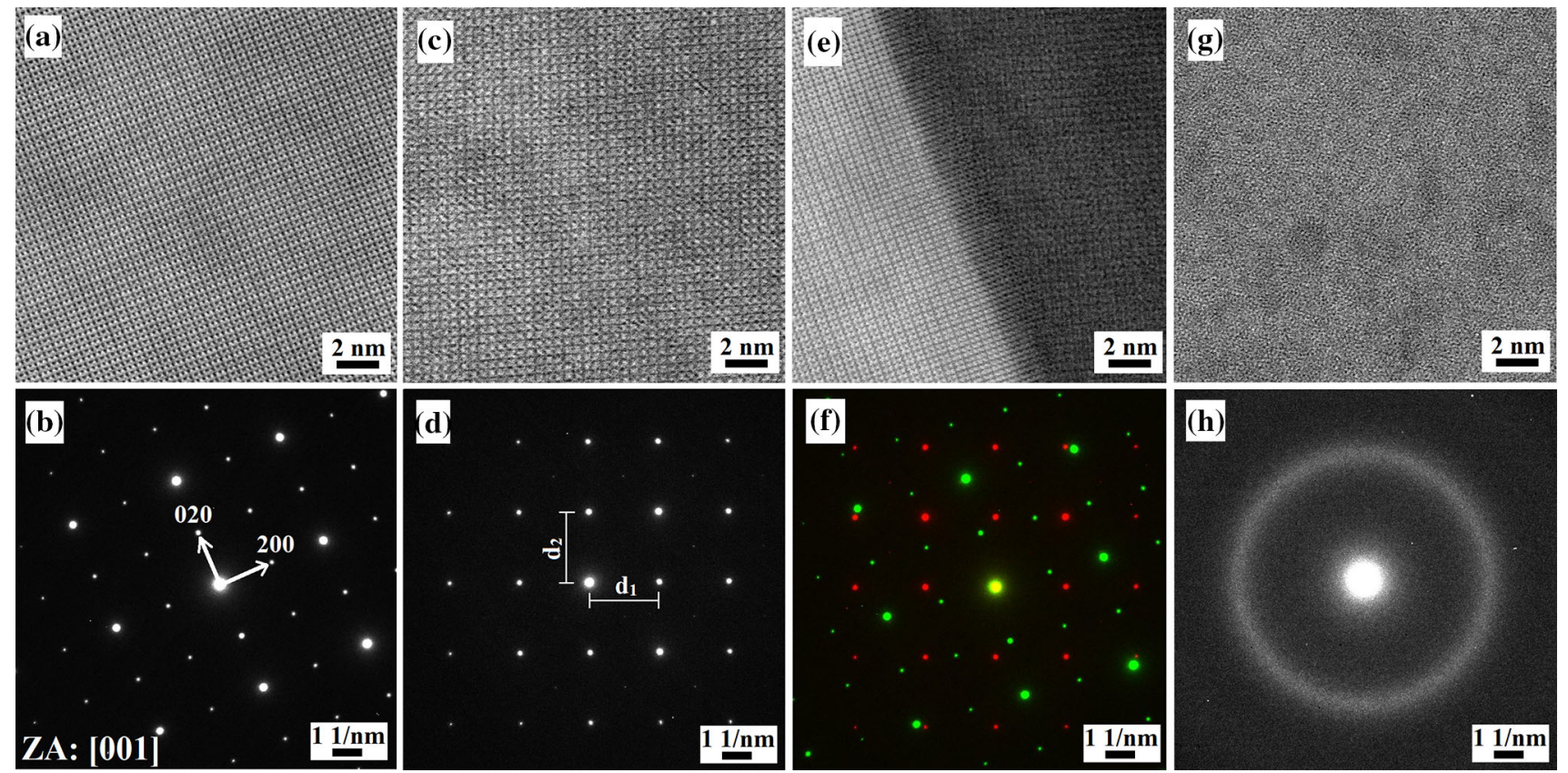

Fig. 5-HRSTEM HAADF images of the $\mathrm{B} 2 / 3$ alloy $\left(\mathrm{Zr}_{49.860} \mathrm{Cu}_{39.890} \mathrm{Al}_{9.972} \mathrm{Y}_{0.281}\right)$ with corresponding diffraction patterns: $(a$, $b) \mathrm{Y}_{2} \mathrm{O}_{3}$ oxide (Iaj-space group), ZA: [001]; $(c, d)$ crystalline $\tau_{3}$ phase $\left(d_{1}=d_{2}=4.26 \AA\right.$ ); $(e, f)$ interface between $\mathrm{Y}_{2} \mathrm{O}_{3}$ and $\tau_{3}$ phases (superposition of diffraction patterns (green $-\mathrm{Y}_{2} \mathrm{O}_{3}$, red- $\left.\left.-\tau_{3}\right)\right) ;(g, h)$ amorphous matrix (Color figure online).

eutectoid transformation of the crystallization products into the $\mathrm{CuZr}$ phase, accompanied by an endothermic event. The start $\left(T_{\mathrm{s}}\right)$ and finish $\left(T_{\mathrm{f}}\right)$ temperatures of this transformation are the same in all cases $(1047 \mathrm{~K}$ and $1078 \mathrm{~K}$, respectively), both in the reference alloys (with high and low oxygen levels) and doped alloys. The last endothermic peaks correspond to the melting process, where $T_{1}$ stand for the end of this event and this value is included in most GFA indicators. In our previous study, ${ }^{[4]}$ we showed that a high oxygen level in the alloy 
causes broadening and splitting of the melting event into two peaks, due to the shifting the alloy to the off-eutectic composition. Here, we may conclude that that increase in yttrium addition decreases the liquidus temperature and narrows the melting range, thereby improving GFA.

Summarized data of $T_{\mathrm{g}}, T_{\mathrm{x}}, T_{\mathrm{p} 1}, T_{1}$ temperatures and calculated GFA indicators, including data of the low oxygen (A) and high oxygen (B) undoped $\mathrm{Zr}_{50} \mathrm{Cu}_{40} \mathrm{Al}_{10}$ alloy, ${ }^{[4]}$ are presented in Table II. Alloy B is characterized by the lowest values for almost all indicators, the highest value (the best GFA) was found for the low oxygen variant, whereas intermediate values were calculated for the $\mathrm{B} 1 / 3, \mathrm{~B} 2 / 3$ and $\mathrm{B} 4 / 3$ alloys. The $T^{\prime \prime}{ }_{\mathrm{rg}}$

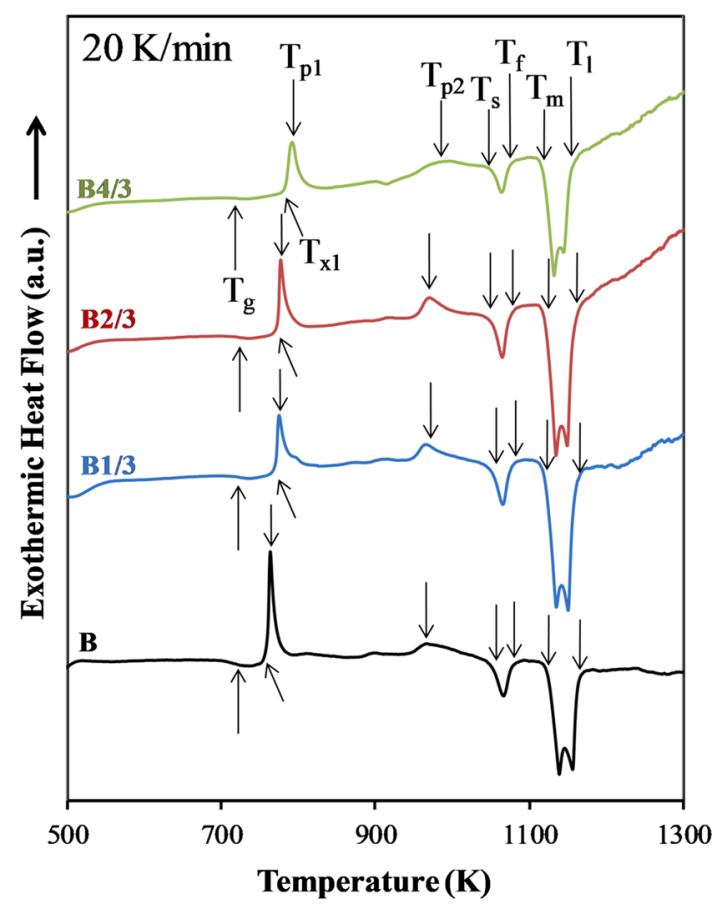

Fig. 6-DTA curves of the studied alloys: B1/3 to $4 \mathrm{~mm}, \mathrm{~B} 2 / 3$ to $5 \mathrm{~mm}, \mathrm{~B} 4 / 3$ to $7 \mathrm{~mm}$, sizes corresponding to the $D_{c}^{r}$, and $\mathrm{B}-3 \mathrm{~mm}$ (reprinted with permission from [4] (C) Elsevier); characteristic temperatures: $T_{\mathrm{g}}$-glass transition, $T_{\mathrm{x}}$ - onset of crystallization, $T_{\mathrm{p} 1}$, $T_{\mathrm{p} 2}$ - first and second peak of crystallization, $T_{\mathrm{s}}$ and $T_{\mathrm{f}}-$ start and finish of the eutectoid transformation, $T_{\mathrm{m}}$ - solidus, $T_{1}$-liquidus. parameter, which includes only $T_{\mathrm{g}}$ and $T_{1}$ temperatures, does not correlate with the critical diameter values. The most sensitive indicators are $\Delta T_{\mathrm{xg}}$ (it varies between $40 \mathrm{~K}$ and $68 \mathrm{~K})$ and $\chi(0.252$ to 0.521$)$ parameters. The GFA is strongly associated with the stability of the liquid phase and its crystallization resistance. On the one hand, although consisting of only two characteristic temperatures $\left(T_{\mathrm{x}}-T_{\mathrm{g}}\right), \Delta T_{\mathrm{xg}-}$ was confirmed to be in good agreement with the critical cooling rate for glass formation. ${ }^{[38]}$ On the other hand, the $\chi$ parameter was confirmed to best correlate the GFA with $D_{\mathrm{c}}{ }^{[35]}$ Figure 7 shows a good linear relationship between these parameters. The $\chi$ value of the undoped $\mathrm{Zr}_{50} \mathrm{Cu}_{40} \mathrm{Al}_{10}$ alloy containing $918 \pm 72$ wt ppm of oxygen (B) was calculated as 0.252 , which corresponds to the critical diameter of $\sim 2.5 \mathrm{~mm}$. Assuming that the critical diameter should be an integer value, we may conclude that $D_{c}^{r}=2 \mathrm{~mm}$.

\section{CONCLUSIONS}

The effect of controlled yttrium addition to the $\mathrm{Zr}_{50} \mathrm{Cu}_{40} \mathrm{Al}_{10}$ alloy, containing $918 \pm 72 \mathrm{wt}$ ppm of oxygen, on glass formation was studied and the following conclusions were drawn:

1. The harmful effect of high oxygen content in Zr-based alloys coming from the low purity of raw materials can be minimized by controlled yttrium doping. The yttrium addition resulted in the formation of a cubic $\mathrm{Y}_{2} \mathrm{O}_{3}$ ( $I a \overline{3}$ space group) instead of a $\mathrm{ZrO}_{2}$ phase, which inhibited the formation of the intermetallic $\tau_{3}$ phase that had previously been observed in the undoped alloy.

2. The stoichiometric addition of yttrium, with respect to the measured oxygen content in the undoped alloy, required to bind all of the oxygen to the $\mathrm{Y}_{2} \mathrm{O}_{3}$ oxide is not sufficient to fully utilize its scavenging effect.

3. The double stoichiometric level of yttrium $(0.562$ at. pct) allowed to obtain a $7 \mathrm{~mm}$ diameter glassy sample, which is only $1 \mathrm{~mm}$ below the critical diameter obtained for the undoped $\mathrm{Zr}_{50} \mathrm{Cu}_{40} \mathrm{Al}_{10}$ alloy produced from elements with low oxygen contents.

Table II. Characteristic Temperatures, Critical Diameters (in Brackets Predicted Value for Alloy B) and GFA Indicators of Reference (A-Low Oxygen Content, B-High Oygen Content, Reprinted with Permission from Ref. [4] (C) Elsevier) and Doped Alloys. A and $B$ Correspond to the $\mathrm{Zr}_{50} \mathrm{Cu}_{40} \mathrm{Al}_{10}$ with Low Oxygen (194 $\left.\pm 26 \mathrm{wt} \mathrm{ppm}\right)$ and High Oxygen (918 $\pm 72 \mathrm{wt}$ ppm), Respectively

\begin{tabular}{|c|c|c|c|c|c|c|c|c|c|c|c|}
\hline \multirow[b]{2}{*}{ Alloy } & \multirow[b]{2}{*}{$D_{c}^{r}(\mathrm{~mm})$} & \multicolumn{4}{|c|}{ Characteristic Temperatures } & \multicolumn{6}{|c|}{ Glass Forming Ability Indicators } \\
\hline & & $T_{\mathrm{g}}(\mathrm{K})$ & $T_{\mathrm{x}}(\mathrm{K})$ & $T_{\mathrm{p} 1}(\mathrm{~K})$ & $T_{1}(\mathrm{~K})$ & $\Delta T_{\mathrm{xg}}(\mathrm{K})$ & $T^{\prime \prime}{ }_{\mathrm{rg}}$ & $\gamma$ & $\gamma_{\mathrm{m}}$ & $\omega_{4}$ & $\chi$ \\
\hline $\mathrm{A}^{[4]}$ & 8 & 711 & 779 & 781 & 1157 & 68 & 0.614 & 0.417 & 0.732 & 0.438 & 0.521 \\
\hline $\mathrm{B}^{[4]}$ & $<3(2)$ & 720 & 760 & 764 & 1163 & 40 & 0.619 & 0.404 & 0.688 & 0.416 & 0.252 \\
\hline $\mathrm{B} 1 / 3$ & 4 & 723 & 770 & 775 & 1158 & 47 & 0.624 & 0.409 & 0.706 & 0.424 & 0.332 \\
\hline $\mathrm{B} 2 / 3$ & 5 & 723 & 773 & 777 & 1157 & 50 & 0.625 & 0.411 & 0.711 & 0.426 & 0.364 \\
\hline $\mathrm{B} 4 / 3$ & 7 & 723 & 783 & 792 & 1154 & 60 & 0.627 & 0.417 & 0.731 & 0.435 & 0.485 \\
\hline \multicolumn{12}{|c|}{ 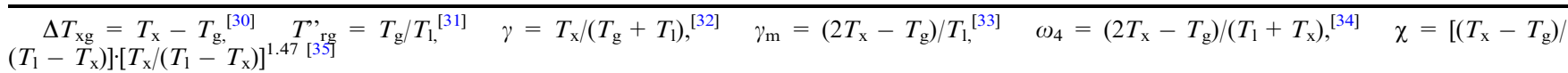 } \\
\hline
\end{tabular}




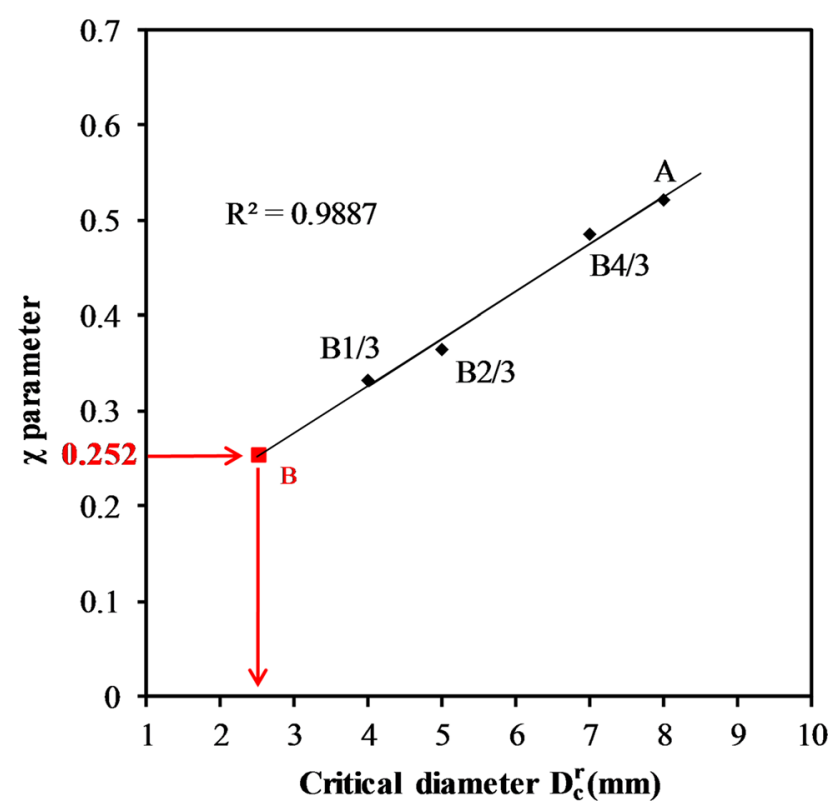

Fig. 7-Relationship between $\chi$ parameter and critical diameter $D_{c}^{r}$. Red lines show the predicted $D_{c}^{r}$ for the undoped $\mathrm{Zr}_{50} \mathrm{Cu}_{40} \mathrm{Al}_{10}$ alloy with a high oxygen level (Color figure online).

4. The increase in yttrium concentration did not influence the glass transition temperature, however, it significantly increased the crystallization temperature and lowered the liquidus temperature. Good agreement between the $\chi$ parameter and $D_{c}^{r}$ allowed to determine the critical diameter of the undoped $\mathrm{Zr}_{50} \mathrm{Cu}_{40} \mathrm{Al}_{10}$ alloy containing $918 \pm 72 \mathrm{wt} \mathrm{ppm}$, which was predicted to be $2 \mathrm{~mm}$.

\section{ACKNOWLEDGMENTS}

This work was financially supported by the Ministry of Science and Higher Education Republic of Poland under contract No. 16.16.110.663. To Elsevier Ltd. for copyright and permissions provided by Copyright Clearance Center (CCC) - www.rightslink.com.

\section{OPEN ACCESS}

This article is licensed under a Creative Commons Attribution 4.0 International License, which permits use, sharing, adaptation, distribution and reproduction in any medium or format, as long as you give appropriate credit to the original author(s) and the source, provide a link to the Creative Commons licence, and indicate if changes were made. The images or other third party material in this article are included in the article's Creative Commons licence, unless indicated otherwise in a credit line to the material. If material is not included in the article's Creative Commons licence and your intended use is not permitted by statutory regulation or exceeds the permitted use, you will need to obtain permission directly from the copyright holder. To view a copy of this licence, visit http://creat ivecommons.org/licenses/by/4.0/.

\section{REFERENCES}

1. A. Inoue and A. Takeuchi: Acta Mater., 2011, vol. 59, pp. $2243-67$

2. E. Axinte: Mater. Des., 2012, vol. 35, pp. 518-56.

3. J. Schroers, G. Kumar, T.M. Hodges, S. Chan, and T.R. Kyriakides: JOM., 2009, vol. 61, pp. 21-29.

4. K. Pajor, T. Kozieł, G. Cios, P. Błyskun, P. Bała, and A. Zielińska-Lipiec: J. Non. Cryst. Solids., 2018, vol. 496, pp. $42-47$.

5. X.H. Lin, W.L. Johnson, and W.K. Rhim: Mater. Trans. JIM., 1997, vol. 38, pp. 473-77.

6. P. Błyskun, T. Kozieł, K. Pajor, P. Maj, and T. Kulik: J. Non. Cryst. Solids., 2019, vol. 509, pp. 80-87.

7. N.D. De Campos Neto, F.S. Pereira, S.G. Antonio, Y. Guo, A.J. Clarke, M.J. Kaufman, and M.F. De Oliveira: Mater. Charact., 2019, vol. 158, pp. 1-7.

8. C.A. Teixeira, R.V. da Silva, L.T. Pereira, and M.F. de Oliveira: $J$. Non. Cryst. Solids., 2020, vol. 535, art. no. 119966.

9. C.T. Liu, M.F. Chisholm, and M.K. Miller: Intermetallics, 2002, vol. 10 , pp. $1105-12$.

10. Z.H. Han, L. He, Y.L. Hou, J. Feng, and J. Sun: Intermetallics, 2009, vol. 17, pp. 553-61.

11. J.L. Cheng, G. Chen, Z.W. Zhang, Z.Z. Wang, Z.Y. Wang, and X.Q. Li: Intermetallics, 2014, vol. 49, pp. 149-53.

12. Y. Yokoyama, T. Shinohara, K. Fukaura, and A. Inoue: Mater. Trans., 2004, vol. 45, pp. 1819-23.

13. J.P. Abriata, J. Garces, and R. Versaci: Bull. Alloy Phase Diagr., 1986, vol. 7, pp. 116-24.

14. H. Bo, J. Wang, S. Jin, H.Y. Qi, X.L. Yuan, L.B. Liu, and Z.P. Jin: Intermetallics, 2010, vol. 18, pp. 2322-27.

15. K.T. Park, T.H. Lee, N.C. Jo, H.H. Nersisyan, B.S. Chun, H.H. Lee, and J.H. Lee: J. Nucl. Mater., 2013, vol. 436, pp. $130-38$.

16. Y. Zhang, M.X. Pan, D.Q. Zhao, R.J. Wang, and W.H. Wang: Mater. Trans. JIM., 2000, vol. 41, pp. 1410-14.

17. W.H. Wang: Prog. Mater. Sci., 2007, vol. 52, pp. 540-96.

18. X.I.E. Zhiwei, Z. Yongzhang, Y. Yuanzheng, C. Xianzhao, T.A.O. Pingjun, Z. Xie, Y. Zhang, Y. Yang, X. Chen, and P. Tao: Rare Met., 2010, vol. 29, pp. 444-50.

19. A.A. Kündig, D. Lepori, A.J. Perry, S. Rossmann, A. Blatter, A. Dommann, and P.J. Uggowitzer: Mater. Trans., 2002, vol. 43, pp. $3206-10$.

20. J. Luo, H. Duan, C. Ma, S. Pang, and T. Zhang: Mater. Trans., 2006, vol. 47 , pp. $450-53$

21. J. Zhu, C. Wang, J. Han, S. Yang, G. Xie, H. Jiang, Y. Chen, and X. Liu: Intermetallics, 2018, vol. 92, pp. 55-61.

22. J. Chen, Y. Zhang, J.P. He, K.F. Yao, B.C. Wei, and G.L. Chen: Scr. Mater., 2006, vol. 54, pp. 1351-55.

23. F. Sikan, B. Yasar, and I. Kalay: Metall. Mater. Trans. A, 2018, vol. 49A, pp. 1328-35.

24. M. Malekan, R. Rashidi, and S.G. Shabestari: Vacuum, 2020, vol. 174, art. no. 109223.

25. S.W. Neale, R. Neelameggham, S. Alam, H. Oosterhof, A.A. Jha, and D. Dreisinger: Rare Metal Technology, Wiley, Hoboken, 2014.

26. R.A. Robie, B.S. Hemingway, and J.R. Fisher: Thermodynamic properties of minerals and related substances at $298.15 \mathrm{~K}$ and 1 Bar pressure and at higher temperatures, United States Government Printing Office, Washington, 1978.

27. M. Zinkevich: Prog. Mater. Sci., 2007, vol. 52, pp. 597-647.

28. I. Halevy, R. Carmon, M.L. Winterrose, O. Yeheskel, E. Tiferet, and S. Ghose: J. Phys. Conf. Ser., 2010, vol. 215, pp. 1-8.

29. K.J. Laws, B. Gun, and M. Ferry: Metall. Mater. Trans. A, 2009, vol. 40 A, pp. $2377-87$.

30. A. Inoue, T. Zhang, and T. Masumoto: J. Non. Cryst. Solids., 1993, vols. 156-158, pp. 473-80.

31. Z.P. Lu, Y. Li, and S.C. Ng: J. Non. Cryst. Solids., 2000, vol. 270, pp. 103-14.

32. Z.P. Lu and C.T. Liu: Acta Mater., 2002, vol. 50, pp. 3501-12. 
33. X.H. Du, J.C. Huang, C.T. Liu, and Z.P. Lu: J. Appl. Phys., 2007, vol. 101 , pp. $23-25$.

34. P. Błyskun, P. Maj, M. Kowalczyk, J. Latuch, and T. Kulik: $J$. Alloys Compd., 2014, vol. 625, pp. 13-17.

35. Z. Long, W. Liu, M. Zhong, Y. Zhang, M. Zhao, G. Liao, and Z. Chen: J. Therm. Anal. Calorim., 2018, vol. 132, pp. 1645-60.

36. K.K. Song, S. Pauly, Y. Zhang, P. Gargarella, R. Li, N.S. Barekar, U. Kühn, M. Stoica, and J. Eckert: Acta Mater., 2011, vol. 59, pp. 6620-30.
37. B. Escher, U. Kühn, J. Eckert, C. Rentenberger, and S. Pauly: Mater. Sci. Eng. A., 2016, vol. 673, pp. 90-98.

38. J. Perepezko, C. Santhaweesuk, J. Wang, and S.D. Imhoff: $J$. Alloys Compd., 2014, vol. 615, pp. S192-97.

Publisher's Note Springer Nature remains neutral with regard to jurisdictional claims in published maps and institutional affiliations. 